\title{
THE ROLE OF ERP SOLUTIONS IN MANAGING CORPORATIONS FROM THE ACCOUNTING PERSPECTIVE
}

\author{
Marko Milojević, \\ Ivica Terzić, \\ Dragan Miletić, \\ Saša Stamenković
}

Singidunum University, 32 Danijelova Street, Belgrade, Serbia

Correspondence:

Marko Milojević

e-mail:

mmilojevic@singidunum.ac.rs

\begin{abstract}
:
Contemporary method of doing business requires that managers have at their disposal at all times information about the results achieved both by the company as a whole and by its individual organizational units or its products and services. In the circumstances characterized by globalism and unhindered movement of capital, monitoring business operations would be unthinkable without integrated business solutions. Activities and processes carried out within an organisation are mutually interconnected and interdependent, and therefore must be synchronised in order to maximise available resources and obtain information in a timely fashion. The implementation of integrated business solutions is precisely what facilitates efficient management of companies that are geographically dispersed and that carry on complex and multiple business operations. The objective of this paper is to analyse the roles and functions which enterprise resource planning (ERPs) solutions have within the business organisation and on improving organisation's efficiency and quality in terms of its business operations and decision-making process.
\end{abstract}

Key words:

accounting information systems, ERPs, costs, investments, resource management.

\section{INTRODUCTION}

The last decade of the twentieth century witnessed the successful implementation of a long-lasting ideal of using a single integrated software package for managing, supervising and controlling all business processes within a legal entity. This software solution was named ERP (Enterprise Resource Planning) or business resource planning system. The ERP structure comprises information subsystems i.e. information modules which deal with individual functional activities (parts) of the company, such as: production, accounting, warehousing, marketing, sales, planning, procurement, finances, human resources, legal affairs, client relationship, etc (Barjaktarović et al., 2015). Individual software applications which process transactions within a business unit or a business process regardless of the company's overall activities are not suitable for planning resources on the level of an entire organisation (Ganesh et al., 2014). Such applications do not meet the needs of modern organisations. Activities and processes of a single organisation are interconnected and interdependent and therefore must be synchronised in order to ensure optimisation of available resources and to obtain timely information (Milojević et al., 2014b). This clarifies 
why the information system must be based on a new, integrated and interconnected concept. The complexity of such system and diversity of organisational functions was precisely what made companies and organisations discard the idea of creating and maintaining their own information system.

Prior to the introduction of ERPs, companies generally owned information systems for each business process and function. It was not a rare case that the company owns one information system used for accounting purposes and the other one for logistics, production and marketing. Such information systems were mainly introduced:

- At different times,

- Often by using different programming tools, and

- Procured from different vendors (Marjanović and Milojević 2012).

This leads to complications and more expensive maintenance of systems implemented in this way. Data and business transactions are frequently recorded more than once, information is unreliable and their exchange made difficult. Reports generated by such systems are often inconsistent and defy comparison. The role and the tasks performed by ERP, and this paper too, are to describe the manner in which ERP integrates data from all company's functional units and converts them into unique and reliable information which is adapted to serve the company's specific needs, in accordance with international business standards.

Today, information is a crucial business resource and each company's efficiency and productivity is directly dependent on possession, analysis and use of information. Modern information and communication technologies (ICT) play a vital and important role across entire globalised market (Marjanović et al., 2014). Tha majority of job positions in modern organisations require the use of computers and IT resources (both software and hardware). Computer literacy of company's employees and the extent to which information technologies are applied within a company is one of the most important factors for the companies to opt for the introduction of ERPs.

The concept of an ERP system implies that individual transactions are parts of an integral set of business processes which are comprised of the company's operations and data generated by such transactions do not pertain only to certain parts of the organisation but can and should be used for diverse purposes by different users dispersed within the organisation. ERP is therefore a multi-modular strategic asset and software tool which enables integration of organisational segments as well as synchronisation of individual business functions into mutually connected business process via a unique information system. In this way, ERP ensures control and optimal use of all company resources and meeting the needs of all information system users (Tumbas 2008; Njeguš 2009). To enable greater flexibility for business operations and modelling of organisation, ERP systems rely on the use of client-server technology, relational databases, Windows and Unix OS and advanced programming languages.

Company's ERP system is comparable to a human central nervous system. If it is healthy i.e. functional, ERP transfers information about supplier, buyer and employee status to the management in an understandable manner. ERP also assists management, the "brain" of the company, in adequately responding to such information and in coordinating company's resources in the manner which can attract new users, defeat the competitors and reduce expenses. For these reasons, the implementation of ERP system can be viewed as the best possible investment. The objective of this paper is to analyse the roles and functions which ERPs have within the business organisation and their effect on the improvement of efficiency and quality of business operations and decision-making processes.

\section{EVALUATION OF ERPS}

The development of integrated information systems started in the 70s of the last century with the introduction of information systems for production planning purposes and which primarily dealt with material resource planning (MRP). Somewhat later, the production operations became linked with the clients' requirements and necessary capacity with the intention to close the circle of orders, procurements, production and sales. Such business systems were closed-loop MRPs. The improvement and development of this system resulted in the so-called MRP II systems in 80s (Nuković 2011). These systems enabled planning and managing all resources required for the production process not just material but also human and financial resources as well. At the beginning of 1990s, the interconnection of all business processes within a single organisation with its suppliers and clients gave rise to the implementation of enterprise resource planning system (ERP). For years, ERP solutions were reserved almost entirely for manufacturing companies but today they are used by all types of organisations. Technological advancement which brought about mass production inspired more careful attitude towards buyer's needs and requirements. Monitoring such requirements resulted in the development of information systems for customer 
relationship management which served to support the production and sales according to clients' needs and requirements. Successful functioning of the abovementioned business process was dependent on the business process performed with the supply chain causing the need to connect to the supply chain information system (SCM - Supply Chain Management) with ERP and CRM. ERP II was a new term launched by the Gartner Group referring to the next generation ERP tools which are expected to provide high quality support to specific business requirements, internal and external communication and human resources management.

ERP systems continuously upgrade their web interfaces to ensure better support to e-trade and company portals and to ensure more simple data exchange via internet. Application Service Providers will play an ever increasingly important role in outsourcing of often very expensive ERP modules. Even though the implementation of ERP is very expensive and time-consuming activity, majority of global companies introduced and applied ERP system. This stresses the actual need for connecting all processes and functions within a company into a unique information system and circumvents the inefficiency resulting from non-integrated data and isolated applications.

\section{REASONS IN FAVOUR OF ERP INTRODUCTION}

There are numerous reasons speaking in favour of introduction of ERPs. Factors and motives which have effects on the decision to invest into ERP are commercial and technological in nature.

Business reasons are the following:

- Optimisation of the use of resources,

- Reduction of operating expenses,

- Increasing productivity and efficiency,

- Synchronisation of planning, management and control.

- Improvement of business cooperation with the clients (buyers) and business partners,

- Improving the decision-making process.

- Technological motives are the following:

- Improving the quality and availability of information,

- Standardisation of business processes in accordance with the best business practices,

- Integration, optimisation and improvement of business processes,
- Introduction of the system which enables the growth and development of business operations in contemporary environment,

- Replacement of non-integrated and outdated systems.

In modern business environment, the speed of organisation's response to market demands is of vital importance. With its unique database and integrated modules, ERP system enables an organisation to make faster and more efficient decisions based on accurate and up-todate information. An alternative to ERP implies keeping large number of unintegrated business applications and systems which support different business functions and processes. Maintaining such systems is very expensive as each of them requires different support and maintenance. In such an unintegrated environment, data must be entered separately into each of those systems. Different systems may require different formats which incurs data conversion costs. Multiple entries also imply more employees to perform them, which only results in higher costs while posing a potential hazard for data integrity and safety as well.

\section{GOALS OF ERP SYSTEMS}

Basic goals of ERP systems may be formulated as follows:

- Integration of financial information (accurate and up-to-date representation of income and expenses);

- Integration of data about clients' orders;

- Standardisation and optimisation of business processes (automation and unification of business process, shorter duration);

- Reduction of inventory (optimal level of supplies with minimum storage costs);

- Standardisation of human resources data (up-todate and accurate) (Petrović et al., 2016).

ERP should be viewed as advancement of previous good business processes. The goal of ERP is to create synergic effects. The most important thing is to adequately perform re-engineering business processes, eliminate no-longer-needed activities and ensure improvement of others as such attitude will enable easier, faster and successful implementation of ERPs (Lečić and Kupusinac 2013). Generally speaking, companies choose an ERP package based on the following factors: functional capabilities, technical characteristics, manufacturers' reputation and implementation costs. The decision regarding the selection of ERP is also affected by the possibility of 
fast implementation, user-friendliness, the scope and extent of necessary adaptations, the level of integration between ERP modules and IT infrastructure support. The most important matter is that ERP solution must meet the requirements of the company/user and it must be actually put to application and be user friendly to the employees and management.

Introduction of ERP changes the decision-making process. However, this does not imply that all activities and processes will be improved "overnight". Whether an ERP will function well depends on the degree of the system's and company's compliance. ERP system provides particular benefits in providing integration of data and exchange of information related to production process, distribution and financial sectors (Milojević et al 2014a).

We have already defined ERP as a complex, integral and comprehensive software solution for business support. However, ERP does not mean only having a unique solution and integration of all business processes, ERP must also have other important characteristics, some of which stand out: flexibility, modularity, openness, independence, comprehensiveness, adaptability, experience and localisation.

Flexibility refers to the system's capability for development in accordance with market changes within the company's organisation, technology and production systems. Modularity refers to the benefit of the company to choose its module and thus dictate the complexity of the applied software solution. This means that not only large, but small companies as well, can use ERPs. The openness enables adapting the ERP to different hardware and software platforms, usually legacy systems i.e. existing systems and also openness for establishing connections with other applications and systems. ERP is not dependent on the company's business processes and organisational structure and on its IT resources (hardware, OS, database management system). The comprehensiveness of ERP means that it supports all business functions, all company's business activities carried out in all industries as ERP is applicable in industry, trade, tourism, banking sector, education, healthcare, transport... Adaptability of ERP arises from its modularity, openness and comprehensiveness - it is adaptable to company's needs and requirements. This characteristic is crucial for the successful ERP implementation in all cases. The experience comes from long-term development of ERP, its solutions were tested in practice many times and are based on the "best business practice". Localisation refers to the "translation" of the software into the local language but also to the adaptability of the domestic law regulations which are often subject to changes.

\section{ERP'S ARCHITECTURE}

ERP is a unit which is comprised of modules which refer to all company's business functions. The modules are interchangeable, modifiable and adaptable and subject to combination in accordance with the company's actual needs and requirements. ERP system, through its modules, manages and controls all company's resources. One of most important information is the management of large quantities of information generated for individual business activities. It is very important that all relevant information is made available to all company's business segments. Decisions are made based on such information, for example: when the activity should start and end, who should perform such activity, which resources should be used and to what extent, etc.

Typical ERP system uses diverse software and hardware components to establish integration of business processes and activities. Key elements of majority of ERP system are their unique databases where data are stored for processing in various modules. The concept of development of ERP system includes the following stages:

- Planning,

- Analysis of requirements;

- Design;

- Implementation;

- Maintenance.

ERP integrates the operation of all organisational units within the company into a unique information system which serves individual needs and requirements. It facilitates data exchange and communication between different business sectors. Each ERP module works separately with its specific function for processing relevant data.

Some of the most significant modules of ERP system are the following:

- Finances \& Accounting,

- Planning \& Budgeting,

- Procurement,

- Warehousing,

- Logistics,

- Human resources,

- Sales \& Distribution,

- Controlling,

- Materials Management,

- Production Management,

- Service Management. 
Additional applications which use ERP resources may be:

- CRM - Customer Relationship Management,

- SCM - Supply Chain Management,

- BI - Business Intelligence.

\section{ADVANTAGES AND DISADVANTAGES OF ERP}

When implementing ERP, every company should become familiar with its advantages and disadvantages and use such knowledge to assess what is the most lucrative course the company should take. The advantages of ERP may be generally classified as organisational, managerial, infrastructure-related, operational and strategic. Here we present the most important advantages and opportunities:

- Single entry of data into the system,

- Data integration,

- Improved information flow,

- More efficient business processes,

- More efficient resource management,

- Improvement of business processes,

- Built-in best business practices and experiences,

- Higher quality planning and decision-making processes,

- Reduction of IT costs;

- Improvement of business skills,

- Improvement of customer relationships.

In addition to its obvious advantages, ERP can also have significant disadvantages such as:

- Implementation is long and expensive and requires large initial investments,

- Requires re-engineering of business processes and organisational changes,

- ERP is a very complex set of tools,

- The ERP implementation project might not bring expected benefits (may even result in company downfall),

- Adaption process may be complicated,

- Errors are replicated (multiplied) through the system,

- Renouncing application which worked well (change of corporate culture),

- Dependence on the supplier (vendor) in the future but also on expert consultants during the implementation,

- High consultancy and license renewal fees,
- Requires permanent training of employees (Manojlov 2013);

ERP market is one of the fastest growing markets in IT industry. The largest and most renowned global vendors of ERPs are SAP, Oracle and Microsoft.

SAP (Systems, Applications and Product in Data Processing) is a German company founded in 1972 and it is currently the industry leader with an estimated $30-60 \%$ share in the global ERP market. Their current product is SAP R/3 ERP system. SAP enjoys a special place among ERP manufacturers due to the fact that its modules were developed internally. Oracle offers Oracle Applications ERP solution which relies on the famous Oracle system for relationship database management with the most popular module being Oracle Financials. Microsoft Dynamics NAV is a mid-size enterprise ERP II class product created by the largest global software vendor - Microsoft, which pursues an adamant strategy of overtaking SAP's leading position. ERP products of all three global leaders are characterised by fast implementation, easy adaptation to user's needs, user-friendliness and efficient interconnection with other systems. All these advantages also come at a (high) price.

The most renowned domestic manufacturers of ERP solutions are companies: AB Soft, Digit, BisERP and (Slovenian) Datalab (ERP Pantheon). We note that there are also so-called open-source solutions, the most famous of them being: Compiere, Openbravo, Open for business OFBiz, ERP 5, WebERP and Tiny ERP. Basic advantages of open-source ERP solutions are the following:

- Possibility of gaining access to source code in which the program was written;

- Free exchange and modification of open code for the purpose of improving program solution,

- The possibility of change and adapting source program,

- The possibility of connecting it with other programming solutions.

Depending on the scope of its business operations and according to its financial possibilities, each company can find an ERP solution suitable for its purposes and a vendor whose product will meet its needs.

\section{COSTS OF ERP}

The cost of ERP system is a central financial issue. Typical cost of ERP ranges between $\$ 400,000$ to $\$ 300$ million EUR. It is estimated that the total average cost of the system per user amounts to approx. $\$ 53,000$. The cost of ERP implementation includes the cost of training, 
consultancy, data analyses and conversion, integration, testing and adaptation. In addition to the price of ERP software, which is rather high, average maintenance costs on annual level amount to about $20 \%$ of its price. This includes software upgrades, expert support and user education through their access to knowledge base.

The structure of costs for introducing ERP is as follows:

- ERP software license costs;

- ERP system maintenance costs;

- Consultancy fees (usually the highest!)

- Costs of adaptation;

- Costs of infrastructure re-engineering;

- Internal associated costs.

The fact that ERP implementation requires large initial financial assets means that small and medium-sized companies are forced not to entertain the thought of ERP implementation at all. However, due to Cloud Computing technology, this issue may be easily circumvented (Jeremić et al., 2015).

Ideal candidates for Cloud ERP service are companies operating in multiple locations. This solution enables the user to access the system from any location and to enter changes to the system which will be immediately recorded in all business processes. Thereby, the system ensures that the current status is always up-to-date as well as fast response to any changes.
Advantages of Cloud ERP are as follows:

- No initial capital costs like those incurred by ERP projects (hardware, software, licenses);

- Monthly payment for resources that you actually use;

- Entitlement to the most up-to-date software versions and software "patches";

- Simple and flexible increase/reduction of the number of users and their access rights (limited access costs less);

- Savings made in respect of time needed for system implementation and adaptation.

Table 1 presents the analysis of costs to be incurred by using ERP on your own IT infrastructure and the use of EPRs on a rented (Cloud) infrastructure. Data clearly show that the rental of Cloud ERP (PaaS - Platform as a Service i.e. SaaS - Software as a Service) is as much as 3.5 times cheaper, plus no initial investments only the costs of monthly subscription.

\section{CONCLUSION}

In recent years, huge changes occurred in the way companies do business. Particular contributors to these circumstances include the following factors: market globalisation, digital economy, growth of ICT sector (cloud computing) and development of e-commerce and e-trade

ERP on your own infrastructure

Investment costs $(€) \quad$ Monthly operating costs $(€)$

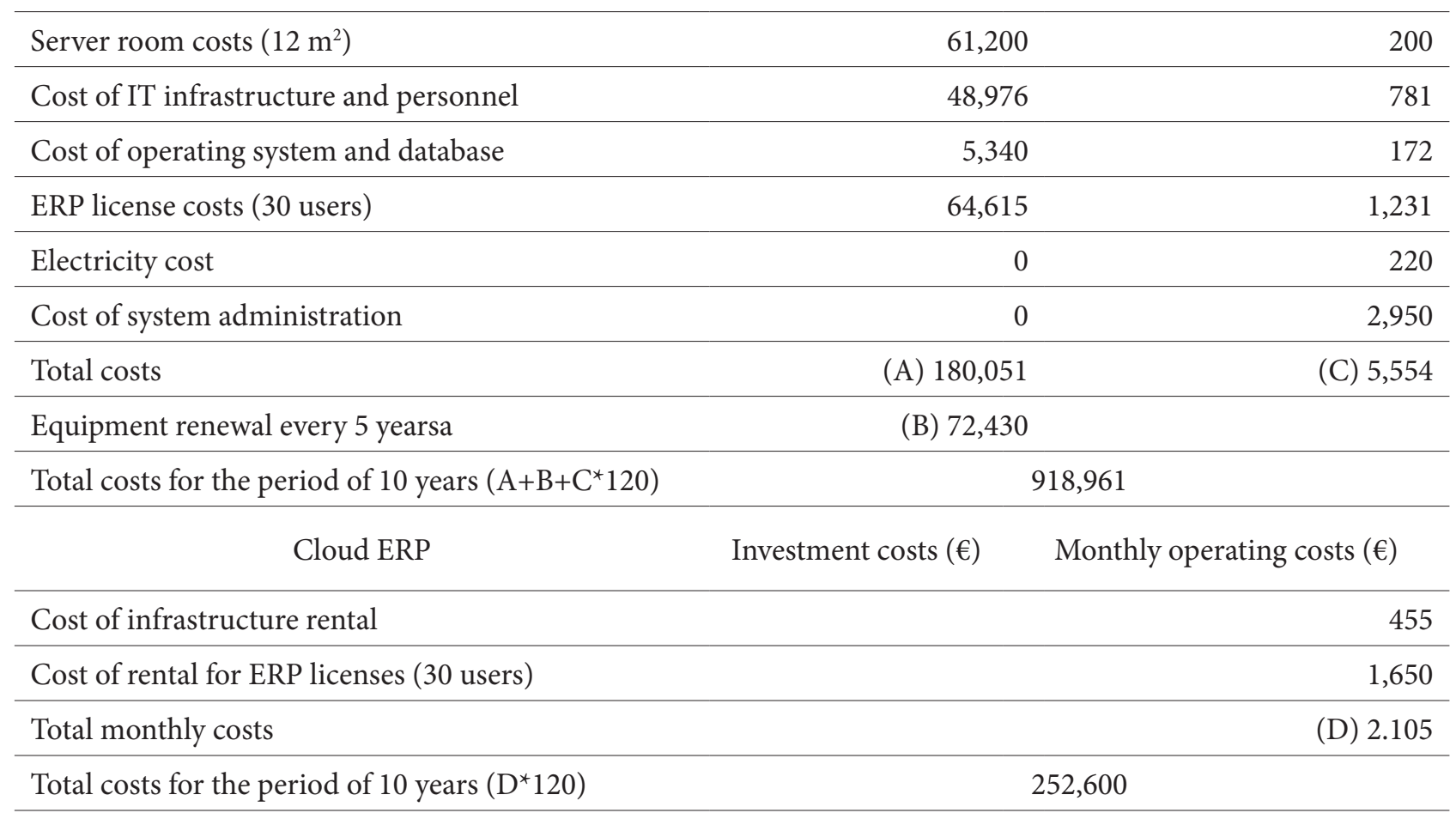

Table 1: ERP Implementation Costs Analysis and Comparison (Source: Author's example.) 
through new models and new sales channels used in order to offer products and services. The degree of innovation is such that it increasing requires from the companies to replace their old information-business systems which no longer cope with the modern way of doing business. Old business applications regularly turn out to be obstacles to developing and introducing of new products and services. Despite plenty of advantages which ERP solutions offer in comparison to partial business applications, each company must analyse in depth their organisational and managing requirements, financial and personnel capabilities and assess their alternatives.

Each business system expect ERP to bring huge benefits: increased productivity, reduced operating expenses, improved business performance, shorter duration of business processes, higher quality and faster information flow, increased customer satisfaction.

To ensure company's survival in the times of harsh economic crises, management must have at its disposal accurate and timely information regarding business performance of each segment of the company. ERP integrates and supports all business processes within a single company through a unique database. Contemporary ERP systems are used by an ever increasing number of employees. The reason is very clear - in addition to financial and accounting operations of the company, information system cover also procurement, sales, human resources, customer relations, etc. Integrated ERP solutions cover and imply regulation of company's business processes, complete control over its business activity, readiness to compete in the market, widening the scope of its business activity, company growth and development.

Both domestic and international markets offer a wide array of high quality ERP solutions which enable businesses and other organisations to make an adequate choice, to select the product which will meet their current needs but will also be adaptable to future changes. Market openness and global digital economy imply the implementation and use of ERP solutions, particularly by large businesses and organisations.

\section{REFERENCES}

Barjaktarović, L., Jović, Z., \& Milojević, M. (2015). Poslovne finansijse. Beograd: Univerzitet Singidunum.

Ganesh K.,Mohapatra S., Anbuudayasankar S.P., \& Sivakumar P. (2014). Enterprise Resource Planning Fundamental of Design and Implementation, 3rd edition, Springer International Publishing Switzerland.

Jeremić, Z., Milojević, M., \& Terzić, I. (2015). Business performance of the largest exporters in Serbia during the period 2008-2014, Ekonomika preduzeća, Vol. LXIII, No. 5-6, pp. 293-305.

Lečić D., \& Kupusinac A. (2013). The Impact of ERP Systems on Business Decision-Making, TEM Journal, 2(4), pp. 323-326.

Manojlov D. (2013). Uticaj ERP-a i automatizacije poslovnih procesa na poslovno odlučivanje i upravljanje kompanijom, doktorska disertacija, Univerzitet Singidunum, Beograd.

Milojević, M., Terzić, I., \& Marjanović, V. (2014). Application of Benford Analisys in detecting anomalies in the financial statements - case of Serbian large companies, Singidunum University International scientific conference Synthesis, Belgrade, 2014. Belgrade, Serbia.

Milojević, M., Vukadinović, P., \& Miletić, D. (2014). Uticaj globalnih mreža i savremenih informacionih sistema na nastanak i razvoj forenzičkog računovodstva u Srbiji. Zbornik radova. XV Međunarodni naučni skup, Sinergija 2014 (pp. 204-208). Bijeljina, Bosna i Hercegovina.

Marjanović, V., \& Milojević, M. (2012). Implementation of DEA model in assessment of short term liquidity level of Serbian food-production companies identified as ECR Adopters. Improving the competitiveness of the public and private sector by networking competences (pp. 385-411). Niš:Ekonomski fakultet.

Marjanović, V., Ulrich, P., \& Milojević, M. (2014.). SAP System performance in cost center accounting: Evidence based on SQL trace reports. Uticaj interneta na poslovanje U Srbiji i svetu - Sinteza. Uticaj Interneta na poslovanje u Srbiji i svetu Sinteza (pp. 546-551). Belgrade, Serbia.

Njeguš A. (2009). Poslovni informacioni sistemi, III izdanje. Beograd: Univerzitet Singidunum.

Nuković M. (2011). Sistemi planiranja resursa organizacije, Univerzitetska misao, vol. 10/2011, str. 78-94, Univerzitet Novi Pazar.

Petrović, Z., Knežević, G., \& Milojević, M. (2016). Računovodsveni informacioni sistem. Beograd: Univerzitet Singidunum.

Tumbas P. (2008). ERP sistemi. Subotica: Ekonomski fakultet. 